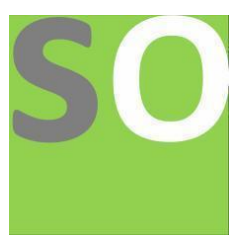

Article title: The Link between Cancer, Autoimmunity and Diabetes

Authors: Domina Petric[1]

Affiliations: Clinical pharmacology and toxicology, University Hospital Center, Soltanska 1, 21000 Split, Croatia[1]

Orcid ids: 0000-0001-5609-1675[1]

Contact e-mail: domina.petric@gmail.com

License information: This work has been published open access under Creative Commons Attribution License http://creativecommons.org/licenses/by/4.0/, which permits unrestricted use, distribution, and reproduction in any medium, provided the original work is properly cited. Conditions, terms of use and publishing policy can be found at https://www.scienceopen.com/.

Preprint statement: This article is a preprint and has not been peer-reviewed, under consideration and submitted to ScienceOpen Preprints for open peer review.

DOI: 10.14293/S2199-1006.1.SOR-.PPXAL5B.v1

Preprint first posted online: 04 October 2021

Keywords: cancer, autoimmunity, diabetes 


\title{
The Link between Cancer, Autoimmunity and Diabetes
}

Domina Petric, MD

\begin{abstract}
In cancer, corrupted neoplastic cell successfully evades the immune attack using two main strategies: avoiding the immune recognition and instigating an immunosuppressive tumor microenvironment. Cancer is able to induce immune tolerance and present itself to immune system as normal tissue. There is a defect in immune tolerance: the tolerance is wrongly induced toward cancer. In autoimmune diseases, immune system attacks normal tissue because it fails to recognize its own constituent parts as self. There is a defect in immune tolerance: the tolerance is lost toward normal tissues. In both diseases wrong information in the communication between tissue (neoplastic) cells and immune system is crucial: in cancer, neoplastic cells avoid immune attack, whilst in autoimmune diseases, immune system attacks normal cells. Diabetes mellitus type I and II are associated with an increased risk of developing different types of cancer. Pathogenesis of diabetes mellitus type I and pathogenesis of cancer overlap in genetic, environmental and immunologic factors. Diabetes mellitus type II and obesity can both induce oncogenesis.
\end{abstract}

INTRODUCTION TO CANCER AND INFLAMMATION

Both autoimmune diseases and cancer stage relates with the functional status of the immune system and circulating levels of cytokines.

Stage I (early onset) is characterized by mild-to-moderate inflammation resulting from recruitment of innate immune cells (for example, myeloid cells) to sites of inflammation. At this stage, inflammation and most tumors are contained within a target organ or diseased (in situ) organs.
Stage II (mild course) is characterized with an evidence of an activated adaptive immune system featuring $\mathrm{T}$ and $\mathrm{B}$ cell proliferation and production of autoantibodies compared with stage I in autoimmune diseases. Tumors are larger than in stage I, but tumor cells remain contained within diseased organs or have started to spread locally into lymph nodes. Tumor-secreted cytokines (GM-CSF, macrophage-CSF, IL-12) can be detected in serum.

Stage III (moderate course or active) is characterized by an intermittent or progressive course that could include 
severe episodes of activity. This stage features predominant recruitment, activation, and proliferation of leukocytes (neutrophils, eosinophils, basophils) at sites of inflammation, including single or multiple target organs or tumors. In this stage there is increased tumor burden and metastatic spread into surrounding tissues and distant lymph nodes.

In stage III of autoimmune diseases many patients exhibit comorbid conditions related to advancement of immunopathology (muscle atrophy in rheumatoid arthritis, moderate nephritis in systemic lupus erythematosus).

Stage IV (severe course) indicates endstage disease. It results in constantly abnormal inflammatory processes associated with severe comorbid conditions and organ failures such as kidney failure in SLE or widespread metastasis for cancer ${ }^{1}$.

Primary and metastatic tumors are complex ecosystems composed of neoplastic cells, extracellular matrix (ECM), and accessory non-neoplastic cells, which include resident mesenchymal support cells, endothelial cells, and infiltrated inflammatory immune cells. Cross-talk between cancer cells and accessory cells fuels and shapes tumor development. During tumor formation, the tissue architecture evolves into a highly specialized microenvironment characterized by a corrupted ECM and chronic inflammation. Cancer-associated inflammation contributes to genomic instability, epigenetic modification, induction of cancer cell proliferation, enhancement of cancer anti-apoptotic pathways, stimulation of angiogenesis, and, eventually, cancer dissemination ${ }^{2,3}$.

Chronic inflammation is a critical hallmark of cancer, with at least $25 \%$ of cancers associated with it $^{4-6}$.

Possible underlying causes of chronic inflammation are microbial infections, autoimmunity, and immune deregulation.

Examples:

1. Human papilloma viruses (HPVs) induce inflammation and are responsible for $90-100 \%$ of all cervical cancers ${ }^{7}$.

2. Chronic infections with Helicobacter pylori elevate the risk for gastric cancer ${ }^{4}$.

3. The immune deregulation seen in inflammatory bowel disease increases colorectal cancer incidence ${ }^{8}$.

4. The nonhuman form of sialic acid (Nglycolylneuroaminic acid) in red meat can be incorporated into human tissue and recruit inflammatory cells ${ }^{9}$. 
5. Tobacco and obesity, both of which induce low-grade inflammation, give rise to elevated risks of cancer ${ }^{10}$.

6. Epstein-Barr virus (EBV) infection, malaria, immunodeficiency and spontaneous, somatic mutation can all contribute to the origin and maintenance of Burkitt lymphoma (aggressive B-cell malignancy $)^{11}$.

7. Systemic lupus erythematosus is associated with an increased risk of developing cervical, lung and breast cancer, as well as Hodgkin and nonHodgkin lymphoma ${ }^{12,13}$.

8. Rheumatoid arthritis is associated with an increased risk of developing lung, breast and ovary cancer, as well as $\mathrm{T}$ cell nonHodgkin lymphoma, follicular lymphoma and diffuse large B cell lymphoma ${ }^{12,13}$.

9. Primary Sjögren syndrome is associated with an increased risk of developing oropharyngeal carcinomas and mucosaassociated lymphoid tissue type B cell lymphoma ${ }^{13,14}$.

10. Systemic sclerosis is associated with an increased risk of developing lung, skin and esophageal cancer ${ }^{13}$.

11. Wegener granulomatosis is associated with an increased risk of developing urinary bladder cancer ${ }^{12}$.

\section{HOW DOES CANCER EVADE THE IMMUNE SYSTEM?}

It is currently accepted than an aberrant innate and adaptive immune response contributes to tumorigenesis by selecting aggressive clones, inducing immunosuppression, and stimulating cancer cell proliferation and metastasis ${ }^{15}$.

Macrophages are crucial drivers of chronic cancer-associated inflammation. Their involvement has been described in every step of cancer progression, from early neoplastic transformation throughout metastatic progression to therapy resistance $\mathrm{e}^{16-18}$.

In oncological patients and preclinical experimental models, high-grade tumorassociated macrophages (TAMs) correlate with poor prognosis and reduced overall survival ${ }^{16,19}$.

TAMs (M2-type, anti-inflammatory, protumorigenic) promote tumor progression in different ways:

1) stimulation of angiogenesis and lymphangiogenesis,

2) stimulation of both cancer cell proliferation and epithelialmesenchymal transition,

3) limitation of the efficacy of therapies, 
4) remodeling of the extracellular matrix,

5) promoting metastasis,

6) and induction

of immunosuppression of anti-tumor effector immune cells $\mathrm{s}^{20-22}$.

High levels of tumor-associated neutrophils (TANs), high levels of neutrophilia, and/or high neutrophil/lymphocyte ratios have been associated with an adverse prognosis in different malignances ${ }^{23,24}$.

NK cells have a well-documented antitumor effect ${ }^{25,26}$. The presence of NK cell infiltration in colorectal and gastric tumors correlates with a favorable outcome ${ }^{27,28}$.

A high level of T-cell infiltration in tumors is associated with a favorable prognosis in melanoma, and breast, lung, ovarian, colorectal, renal, prostate and gastric cancer $^{17,}{ }^{29-37}$. The presence of tumorinfiltrating $\mathrm{CD}^{+} \mathrm{T}$ cells and Th-1 cytokines in tumors correlates with a favorable prognosis in terms of overall survival and a disease-free survival in many malignancies. But, cancer cells exploit the immunosuppressive properties of $\mathrm{T}$ cells while impairing the effector functions of anti-tumor $\mathrm{T}$ cells, such as their ability to infiltrate tumors and their survival, proliferation, and cytotoxicity ${ }^{38}$.
Most neoplastic cells expressing highly immunogenic antigens will be recognized and killed by $\mathrm{T}$-cells during the early stages of tumor development ${ }^{39}$.

The less immunogenic cancer cells escape the immune control of $\mathrm{T}$ cells and survive (cancer immune editing) ${ }^{40}$.

The final outcome is that the surviving cancer cells adopt an immune-resistant phenotype.

To conclude, tumor cells evade the immune attack using two main strategies: avoiding the immune recognition and instigating an immunosuppressive tumor microenvironment.

\section{AVOIDANCE OF THE IMMUNE RECOGNITION}

Cancer cells may lose the expression of tumor antigens on the cell surface, thus avoiding the recognition by cytotoxic $\mathrm{T}$ cells.

Examples:

1. $40 \%$ of non-small cell lung cancers hold a loss of heterozygosity in human leukocyte antigens (HLAs), which leads to immune escape by presenting fewer antigens $^{41}$.

2. HLA loss has been associated with resistance to $\mathrm{T}$-cell transfer therapy in metastatic colorectal cancer ${ }^{42}$. 
3. HLA loss has been associated with poor outcome response to checkpoint blockade immunotherapy in melanoma and lung cancer patients ${ }^{43}$.

\section{IMMUNOSUPPRESSIVE TUMOR MICROENVIRONMENT}

Cancer cell-derived factors instigate an immune-tolerant tumor microenvironment by various mechanisms:

1. Secretion of suppressive molecules such as IL-10, TGF- $\beta$, prostaglandin E2 and VEGF $^{44-47}$.

2. Expression of inhibitory checkpoint molecules such as PD-L1, CTLA-4, and V domain immunoglobulin suppressor of $\mathrm{T}$ cell activation (VISTA) ${ }^{48-50}$.

3. Induction of the recruitment of TAMs (tumor-associated macrophages), MDSCs (myeloid-derived suppressor cells), and Tregs by tumor-derived chemokines such as CCL2, CSF1, CCL5, CCL22, CXCL5, CXCL8, and CXCL12 22,51-53.

\section{AUTOIMMUNITY}

Autoimmunity is the mechanism where an organism fails to recognize its own constituent parts as self, which results in an immune response against its own cells and tissues $^{54,55}$.
Mechanisms of autoimmune diseases are:

\section{Bypass of helper T-cell tolerance.} Tolerance of $\mathrm{CD}^{+}$helper $\mathrm{T}$ cell may be broken if the helper $\mathrm{T}$ cells are bypassed or substituted.

\section{Emergence of sequestered antigen.} The induction of tolerance requires interaction between the antigen and the immune system. Any self-antigen that is completely sequestered during development is likely to be viewed as foreign if introduced into circulation.

\section{Imbalance of suppressor helper T-cell} function. A loss of suppressor $\mathrm{T}$ cell function will contribute to autoimmunity. Excessive T-cell helper function may drive B cells to extremely high levels of autoantibody production.

\section{Microbial agents in autoimmunity.} Microbes (bacteria, mycoplasmas, viruses) may trigger autoimmunity. Viral antigens and autoantigens may become associated to form immunogenic units and bypass $\mathrm{T}$ cell tolerance. EBV is polyclonal B-cell mitogen and may induce formation of autoantibodies. Viral infection may result in loss of suppressor T-cell function.

5. Molecular mimicry. Some infectious agents cross react with human tissues and their haptenic determinants. The infectious microorganisms may trigger an antibody 
response by presenting the cross reacting haptenic determinants in association with their own carrier to which helper T-cells are not tolerant. The antibody so formed may then damage the tissue that shares cross reacting determinants.

\section{Polyclonal lymphocyte activation.} Some microorganisms and their products are capable of causing polyclonal (antigen nonspecific) activation of $B$ cells. Bacterial lipopolysaccharide (endotoxin) can induce mouse lymphocyte to form anti-DNA, antithymocyte and anti-red cell antibodies in vitro ${ }^{56}$.

\section{INTRODUCTION TO CANCER AND} TYPE I DIABETES

Carstensen and coworkers found in the five-country study (Australia, Denmark, Finland, Scotland and Sweden) that, on average, type 1 diabetes confers an excess incidence of several cancers. In particular, persons with type 1 diabetes had a higher incidence of cancer of the liver, pancreas, kidney, endometrium and ovary and a lower incidence of prostate cancer than those in the general population (possibly because of the lower testosterone levels present in men with diabetes). However, similar to the findings for type 2 diabetes, the HRs (hazard ratios) of cancer were highest at time of diabetes diagnosis and declined over time. They also found an increased risk of thyroid cancer in persons with type 1 diabetes compared with the general population, particularly among women ${ }^{57,58}$.

\section{OVERLAPPING GENETIC AND IMMUNOLOGIC FACTORS IN DIABETES TYPE I AND CANCER}

Type 1 diabetes mellitus (T1DM) represents only around $10 \%$ of the diabetes cases worldwide, but occurs with increasing incidence much earlier in life. T1DM results from the autoimmune destruction of $\beta$ cells of the endocrine pancreas. A small percentage of affected patients $(<10 \%)$ are classified as type $1 \mathrm{~B}$, with no evidence of autoimmunity and the pathogenesis in these cases is considered idiopathic ${ }^{59-61}$.

\section{Major histocompatibility complex}

More than $90 \%$ of the patients with T1DM have either HLA-DR3, DQB1*0201 (DR3DQ2) or HLA-DR4, DQB1*0302 (DR4DQ8) haplotypes compared to $40 \%$ of the healthy individuals. About $30 \%$ of the patients have both haplotypes (DR3/4 heterozygotes ${ }^{62,63}$ ). The presence of some DR4 alleles (DRB1*0403, DPB1*0402) reduces the risk of T1DM development even in the presence of DQB $1 * 0302$ highrisk allele. The HLA allele DQB1*0602 
provides protection against T1DM development ${ }^{60,64,65}$.

Kübler and coworkers conducted a study with a sample of 52 Caucasian patients with primary ovarian carcinoma and 239 female healthy local controls. They observed a significantly increased incidence of the HLA-class II haplotypes DRB1*0301-DQA1*0501--DQB1*0201 $(p<0.001)$ and DRB1*1001 - DQA $1 * 0101$ - DQB1*0501 $(p<0.001)$ in the patients with primary ovarian carcinoma ${ }^{66}$.

Machulla and coworkers found in their study on German patients that the presence of alleles HLA-DRB1*0401, HLADQB1*0302 and HLA-DPB1*0301 was associated with a higher risk for chronic lymphocytic leukemia ${ }^{67}$.

Examples of genetic links between T1DM and cancer are DQB1*0201, DQB1*0302.

\section{CTLA-4 (cytotoxic T lymphocyte antigen-4)}

Polymorphisms of CTLA-4 have been associated with T1DM and with other autoimmune diseases. These polymorphisms lead to decreased intracellular expression of the protein; therefore, excessive stimulation and proliferation of $\mathrm{T}$ lymphocytes is not inhibited resulting in uncontrolled progression of immune response and autoimmune imbalance ${ }^{68,69}$.
CTLA-4 signaling has been shown to dampen immune responses against infections and tumor cells $\mathrm{s}^{70}$, 71 . If the CTLA-4 signaling is suppressed, immune response is activated. Anti-CTLA-4 therapies are used against highly immunogenic cancers, such as melanoma ${ }^{72}$. Anti-CTLA-4 therapies can increase the risk of autoimmunity (iatrogenic autoimmunity). Nivolumab and ipilimumab treatment may increase risk of developing autoimmune joint and tissue disease $^{73}$.

CTLA-4 signaling suppression, whether is caused by genetic polymorphism or by anti-CTLA-4 cancer therapy, is associated with the higher risk for the development of T1DM and other autoimmune diseases.

3. Protein tyrosine phosphatase nonreceptor type 22 (PTPN22)

A missense mutation in the PTPN22 gene (C1858T polymorphism; Arg620Trp) was found to be associated with T1DM because it decreases the binding affinity of lymphoid tyrosyl phosphatase (LYP) to inactivating kinase (CSK), leading to uncontrolled T-cell activation and autoimmune reaction $^{74,75}$.

Genetic manipulation of PTPN22 expression might enhance the efficacy of anti-tumor T-cell responses ${ }^{76}$. 
Systemic inhibition of PTPN22 can enhance the anticancer immunity ${ }^{77}$, but it could also increase the risk for autoimmune diseases, including T1DM.

\section{AIRE}

Patients with mutations in the AIRE gene (AIRE protein is an autoimmune regulator, a transcription factor which controls the expression of many specific autopeptides), located on the long arm of the chromosome 21 (21q22.3), exhibit autoimmune polyendocrine syndrome 1 (APS 1), also known as APECED syndrome. APE stands for polyendocrine autoimmunity (Addison 's disease, hypoparathyroidism, T1DM), C stands for candidiasis, ED stands for ectodermal dystrophy ${ }^{78,79}$.

Kalra and coworkers showed in their study that AIRE finds differential expression in androgen-dependent and androgenindependent prostate cancer cells. AIRE expression is more in androgenindependent cells due to its regulation by transcription factor Elk-1. These enhanced levels of AIRE modulate the prostate tumor microenvironment by transcriptionally activating a malignancy gene IL-6 in androgen-independent cells. AIRE prevents the cancer cells from anticancer drug-induced death and enhances their invasiveness. AIRE by modulating the cytokine milieu skews the tumor-associated macrophage polarization towards M2 phenotype with increased CD206 and CD163 expression. Subcutaneous mouse model of prostate cancer revealed $\mathrm{AIRE}^{+/+}$mice forming a palpable tumor and presents lymphadenopathy however, only a small benign tumor is observed in $\mathrm{AIRE}^{-/-}$mice and lymph nodes appear normal in size. In conclusion, these findings suggest AIRE as a probable factor in promoting prostate cancer progression ${ }^{80}$.

Results of another study conducted by Nguyen and coworkers indicate that AIRE is induced in oral squamous cell carcinoma and supports cancer-related gene expression in cooperation with ETS1 (proto-oncogene) $^{81}$.

Data from a study conducted by Bianchi and coworkers highlight that AIRE expression in breast cancer is associated with a better prognosis. Imbalance of cellular homeostasis, caused by AIRE transcriptional function, is a new unusual mechanism to trigger apoptosis in breast cancer cells ${ }^{82}$.

\section{FoxP3}

The gene of the transcription factor FoxP3 encodes for a protein scurfin. In humans, congenital dysfunction of FoxP3 leads to an autoimmune polyendocrine disorder associated with chromosome X (IPEX 
syndrome) and is manifested with a milder phenotype comprising of T1DM, allergies, enteropathies and eczema ${ }^{83}$.

FoxP3 transcription factor can be observed as the main component of the immune system expressed in regulatory $\mathrm{T}$ (Treg) cells that regulate hemostasis and selftolerance. The altered expression of FoxP3 was found in autoimmune diseases, benign tumors and carcinomas. Latest reports indicate that the FoxP3 gene mutation can contribute to carcinogenesis, which can be associated with immune response abnormalities $^{84}$. FoxP3 can act as a coactivator to facilitate the Wnt-b-catenin signaling pathway, inducing epithelialmesenchymal transition, tumor growth and metastasis in non-small cell lung carcinoma $^{85}$. FoxP3 expression is associated with degree of gastric cancer differentiation. Upregulated and ectopic tumoral FoxP3 can promote gastric cancer proliferation, migration, and invasion, partly through the TGF- $\beta$ pathway ${ }^{86}$.

\section{STAT3}

Mutations in the STAT3 transcription factor (that is involved in Th1 differentiation) have been identified as monogenic causes of autoimmune diseases. De novo activating mutations of STAT3 are associated with an early onset spectrum of autoimmune diseases, such as T1DM and autoimmune thyroid dysfunction ${ }^{87}$.

Aberrant/unrestrained STAT3 activity is detected in a wide variety of tumors, driving multiple pro-oncogenic functions. STAT3 is widely considered as an oncogene, but STAT3 can elicit different and sometimes contrasting effects under different conditions. STAT3 activities have been shown to be either pro-oncogenic or tumor-suppressive according to the tumor etiology/mutational landscape ${ }^{88}$.

STAT3 is persistently activated in melanoma, multiple myeloma, breast, prostate, ovarian, and colon cancers, thus contributing to malignant transformation and progression. STAT3 is an attractive therapeutic target for cancers ${ }^{89}$.

\section{HIP14}

Knockdown of HIP14 genes (HuntingtinInteracting Protein 14 gene, located on chromosome 12, encodes for a palmitoyl transferase) in mice revealed increased apoptosis for pancreatic $\beta$ cells $^{90,91}$.

Ducker and coworkers showed in the study that HIP14 is over-expressed in a number of human cancers, including colon, stomach, prostate, lung, and breast. The increase in expression may correlate with increased severity of the disease. HIP14 may be a good pharmacodynamic marker for these diseases, as well as a viable target 
for their treatment ${ }^{92}$. High mRNA expression of HIP14 is an unfavorable prognostic marker in renal cancer ${ }^{93}$.

\section{ERBB3}

The Erb-B2 receptor tyrosine kinase 3 gene (located on chromosome 12) seems to play an important role in cytokine-induced apoptosis of $\beta$ cells $^{94}$.

HER3, a member of the EGFR family of receptor tyrosine kinases coded by the ERBB3 gene, plays an important role in cancer, despite its lack of intrinsic kinase activity. Oncogenic ERBB3 somatic mutations are potential tumor drivers ${ }^{95}$.

\section{Other genetic factors: insulin-VNTR} polymorphism $(10 \%$ of the genetic predisposition for T1DM, big class allele is protective $^{96,}{ }^{97}$ ) and IFIH1 (the gene encodes the MDA5 protein, rare variants of IFIH1 through a lost or reduced expression of the protein are protective against T1DM, common IFIH1 single nuclear polymorphisms are associated with the disease $^{98,99}$ ).

\section{OVERLAPPING ENVIRONMENTAL FACTORS IN DIABETES AND CANCER}

\section{VIRUSES}

Children exposed during fetal life to rubella have an increased incidence of
$\mathrm{T} \mathrm{DM}^{100}$. Enteroviruses can play an important role in the early phase of the development of T1DM through the activation of innate immunity ${ }^{101}$.

In T1DM, the best studied paradigm of molecular mimicry is the $\mathrm{P} 2-\mathrm{C}$ protein of the Coxsackie B4 virus. Clones from T-cell lines, that recognize both GAD65 (enzyme found in $\beta$ cells of endocrine pancreas) and P2-C peptides (virus protein), react with both, what results with the destruction of $\beta$-cells of the pancreas ${ }^{102,103}$.

Viruses also play an important role in the pathogenesis of cancer. For example, human papilloma viruses induce inflammation and are responsible for 90$100 \%$ of all cervical cancers ${ }^{104}$. EpsteinBarr virus infection can contribute to the origin and maintenance of Burkitt lymphoma ${ }^{105}$.

\section{DIET}

In several studies, associations of early introduction in the infant's diet of cow's milk with an increased risk for the disease have been reported supporting that infant's exposure to insulin contained in the milk is triggering the autoimmune response ${ }^{106}$. Early integration of cereals into the diet ${ }^{107}$, nitrate exposure from water intake ${ }^{108}$, inadequate intake of omega-3 fatty acids ${ }^{109}$ and vitamin D deficiency ${ }^{110,}{ }^{111}$, have also been implicated. 
Pathogens in cow's meat and milk may cause cancer in humans, according to findings from the German Cancer Research Centre (DKFZ). Pathogens dubbed "Bovine Milk and Meat Factors" found in healthy cows may cause a chronic inflammatory reaction in tissues, such as breast and colon, that can promote cancer. These cancers may take decades to manifest after the person consumes the milk or meat from a cow ${ }^{112}$.

\section{GUT MICROBIOTA}

Patients with T1DM exhibit differences in their gut microbiota compared to healthy controls, specifically a reduced Firmicutes vs. Bacteroidetes ratio ${ }^{113,114}$.

Gastrointestinal dysbiosis has been linked with both local and distant tumors ${ }^{115}$.

The product of the cytotoxin associated gene A (CagA) from Helicobacter pylori, induces the proteasome-mediated degradation of p53 in gastric epithelial cells, by interfering with the host's AKT pathway, thus promoting the rise of gastric cancer $^{116}$. Enterococcus faecalis produces extracellular superoxide and derivative oxygen species capable to diffuse into host's cells. In turn, the increase in the oxidative milieu enhances the possibility of host's cellular DNA mutations ${ }^{117}$.

Fusobacterium nucleatum inhibits for its own advantage host's Natural Killer (NK) cells, in order to recruit at the site of the infection myeloid suppressor cells, therefore indirectly helping cancer genesis $^{118}$. Bacteroides fragilis is able to activate the host's spermine oxidase, which, in turn, generates hydrogen peroxide and reactive oxygen species (ROS)-induced accumulation of DNA damage ${ }^{119}$.

When gut dysbiosis is coupled with an increase in the $\beta$-glucuronidase-secreting bacteria, such as Clostridium leptum and Clostridium coccoides, the enzyme deconjugates liver-catabolized and plantderived estrogens, enabling them to bind and activate the estrogen receptors expressed by target cells. Estrogen receptors activation promotes cell proliferation in tissues responding to estrogens, as breast and endometrium ${ }^{120,121}$. LGG (Lactobacillus rhamnosus GG) is a very good example of a probiotic well studied in cancer, often administered as complementary therapeutic to cure dysbiosis. Given the observed functions as anti-inflammatory and anti-cancer agent in both cellular and animal models, this probiotic may be suggested to be further characterized as adjuvant in integrated anti-cancer therapies in the future ${ }^{122}$. 


\section{CANCER AND TYPE II DIABETES}

Type II diabetes is associated with an increased risk for several cancers, including colon, postmenopausal breast, pancreatic, liver, endometrial, and bladder cancers and non-Hodgkin lymphoma. TIIDM is linked to a modest decrease in the risk for prostate cancer, but does not reduce aggressive forms, and prostate cancer mortality rates are higher among men with diabetes ${ }^{123}$.

Elevated levels of insulin or C-peptide (biomarker of insulin production) predict increased risk for colorectal, postmenopausal breast, pancreatic, bladder, and endometrial cancers ${ }^{124,125}$.

Some evidence suggests that cancer cells may be particularly affected by hyperinsulinemia because of an increased concentration of insulin receptors, often in a form that is particularly mitogenic ${ }^{126,127}$.

Human population studies link higher levels of IGF-1 (insulin-like growth factor1), seen in TIIDM, with an increased risk for colorectal and estrogen receptorpositive breast cancer and possibly prostate and other cancers ${ }^{124,125,128,129 .}$

Hyperinsulinemia decreases liver production of sex hormone-binding globulin, which increases estrogen bioavailability, and together with obesity increases the risk for postmenopausal breast and endometrial cancers ${ }^{130,131}$.

TIIDM and obesity are both characterized by chronic low-grade inflammation, which increases production of free radicals that can disrupt insulin signaling and damage DNA, what can lead to cancer ${ }^{126,132}$.

Obesity is associated with high levels of leptin and decreased production of adiponectin. Population studies link elevated leptin to increased incidence of colorectal, postmenopausal breast, and potentially other cancers. Reduced adiponectin may promote cancer development through increased insulin resistance and inflammation or through changes in cell signaling that increase cell proliferation and angiogenesis ${ }^{127,133}$.

Hyperglycemia increases production of free radicals and other reactive molecules, which could produce oxidative damage to DNA, leading to mutations in oncogenes and tumor suppressor genes ${ }^{126}$.

\section{CONCLUSION}

In cancer, corrupted neoplastic cell successfully evades the immune attack using two main strategies: avoiding the immune recognition and instigating an immunosuppressive tumor microenvironment. Cancer is able to 
induce immune tolerance and present itself to immune system as normal tissue. There is a defect in immune tolerance: the tolerance is wrongly induced toward cancer. In autoimmune diseases, immune system attacks normal tissue because it fails to recognize its own constituent parts as self. There is a defect in immune tolerance: the tolerance is lost toward normal tissues.

In both diseases wrong information in the communication between tissue (neoplastic) cells and immune system is crucial: in cancer, neoplastic cells avoid immune attack, whilst in autoimmune diseases, immune system attacks normal cells.

Wrong information is written in human genome as mutation (genetic susceptibility for either cancer or autoimmune diseases) and is translated on the molecular level after a second hit (infection, toxins, radiation, protein-energy malnutrition, deficiencies of trace minerals and vitamins, psychological stress, chronic inflammation, tobacco, obesity, diabetes, alcohol abuse...). Although cancer and autoimmune diseases are based on completely different type of wrong information, both diseases are associated with chronic inflammation.

Autoimmune diseases are associated with an increased risk of developing some solid tumors and hematologic malignancies. Immune therapy used in some types of cancer is associated with an increased risk of developing iatrogenic autoimmune diseases. Therefore, the art of immunomodulatory therapies is to find a balance between achieving both anticancer and anti-autoimmune effect.

Diabetes mellitus type I and II are associated with an increased risk of developing different types of cancer. Pathogenesis of diabetes mellitus type I and pathogenesis of cancer overlap in genetic, environmental and immunologic factors. Diabetes mellitus type II and obesity can both induce oncogenesis. Protective factors for both diabetes and cancer overlap, such as healthy balanced diet with optimal level of micronutrients, ideal body weigh, healthy gut microbiota, antioxidant therapy, avoidance of toxin exposure and prevention of some bacterial and viral infections (Helicobacter pylori, HPV, EBV, Enteroviruses, Coxcackie B4 virus, gastrointestinal dysbiosis).

\section{REFERENCES}

1. Valencia JC, Egbukichi N, Erwin-Cohen RA. Autoimmunity and Cancer, the Paradox Comorbidities Challenging Therapy in the Context of Preexisting Autoimmunity. J Interferon Cytokine Res. 2019;39(1):72-84. 
2. Gonzalez H, Hagerling C, Werb Z. Roles of the immune system in cancer: from tumor initiation to metastatic progression. Genes Dev. 2018;32(1920):1267-1284.

3. Hanahan D, Weinberg RA. Hallmarks of cancer: the next generation. Cell. 2011;144:646-674.

4. Hussain SP, Amstad P, Raja K, et al. Increased p53 mutation load in noncancerous colon tissue from ulcerative colitis: a cancer-prone chronic inflammatory disease. Cancer Res. 2000;60:33333337.

5. Coussens LM, Werb Z. Inflammation and cancer. Nature. 2002;420:860-867.

6. Beaugerie L, Svrcek M, Seksik P, et al. Risk of colorectal high-grade dysplasia and cancer in a prospective observational cohort of patients with inflammatory bowel disease. Gastroenterology. 2013;145:166-175 e168.

7. Bosch FX, Lorincz A, Munoz N, et al. The causal relation between human papillomavirus and cervical cancer. J Clin Pathol. 2002;55:244-265.

8. Lakatos PL, Lakatos L. Risk for colorectal cancer in ulcerative colitis: changes, causes and management strategies. World J Gastroenterol. 2008;14:3937-3947.

9. Samraj AN, Pearce OM, Laubli H, et al. A red meat-derived glycan promotes inflammation and cancer progression. Proc Natl Acad Sci. 2015;112: $542-547$.

10. Howe LR, Subbaramaiah K, Hudis CA, Dannenberg AJ. Molecular pathways: adipose inflammation as a mediator of obesity-associated cancer. Clin Cancer Res. 2013;19:6074-6083.
11. Brady G, MacArthur GJ, Farrell PJ. EpsteinBarr virus and Burkitt lymphoma. J Clin Pathol. 2007;60(12):1397-1402.

12. Giat E, Ehrenfeld M, Shoenfeld Y. Cancer and autoimmune diseases. Autoimmun Rev. 2017;16:1049-1057.

13. Malaguarnera $\mathrm{M}$, Cristaldi E, Romano G, Malaguarnera L. Autoimmunity in the elderly: implications for cancer. J Cancer Res Ther. 2012;8:520-527.

14. Bernatsky S, Ramsey-Goldman R, Clarke A. Malignancy and autoimmunity. Curr Opin Rheumatol. 2006;18:129-134.

15. Palucka AK, Coussens LM. The basis of oncoimmunology. Cell. 2016;164:1233-1247.

16. Noy R, Pollard JW. Tumor-associated macrophages: from mechanisms to therapy. Immunity. 2014;41:49-61.

17. Kitamura T, Qian BZ, Pollard JW. Immune cell promotion of metastasis. Nat Rev Immunol. 2015;15:73-86.

18. Gonzalez H, Robles I, Werb Z. Innate and acquired immune surveillance in the postdissemination phase of metastasis. FEBS J. 2018;285:654-664.

19. Zhang QW, Liu L, Gong CY, et al. Prognostic significance of tumor-associated macrophages in solid tumor: a meta-analysis of the literature. PLoS One. 2012;7:e50946.

20. DeNardo DG, Brennan DJ, Rexhepaj E, et al. Leukocyte complexity predicts breast cancer survival and functionally regulates response to chemotherapy. Cancer Discov. 2011;1:54-67.

21. Qian BZ, Zhang H, Li J, et al. FLT1 signaling in metastasis-associated macrophages activates an 
inflammatory signature that promotes breast cancer metastasis. J Exp Med. 2015;212:1433-1448.

22. Mantovani A, Marchesi F, Malesci A, et al. Tumor-associated macrophages as treatment targets in oncology. Nat Rev Clin Oncol. 2017;14:399416.

23. Keizman D, Ish-Shalom M, Huang P, et al. The association of pre-treatment neutrophil to lymphocyte ratio with response rate, progression free survival and overall survival of patients treated with sunitinib for metastatic renal cell carcinoma. Eur J Cancer. 2012;48:202-208.

24. Donskov F. Immunomonitoring and prognostic relevance of neutrophils in clinical trials. Semin Cancer Biol. 2013;23:200-207.

25. Marcus A, Gowen BG, Thompson TW, et al. Recognition of tumors by the innate immune system and natural killer cells. Adv Immunol. 2014;122:91-128.

26. Iannello A, Thompson TW, Ardolino M, et al. Immunosurveillance and immunotherapy of tumors by innate immune cells. Curr Opin Immunol. 2016;38:52-58.

27. Coca S, Perez-Piqueras J, Martinez D, et al. The prognostic significance of intratumoral natural killer cells in patients with colorectal carcinoma. Cancer. 1997;79:2320-2328.

28. Ishigami S, Natsugoe S, Tokuda $\mathrm{K}$, et al. Prognostic value of intratumoral natural killer cells in gastric carcinoma. Cancer. 2000;88:577-583.

29. Clemente CG, Mihm MC Jr, Bufalino R, et al. Prognostic value of tumor infiltrating lymphocytes in the vertical growth phase of primary cutaneous melanoma. Cancer. 1996;77:1303-1310.
30. Oldford SA, Robb JD, Codner D, et al. Tumor cell expression of HLA-DM associates with a Th1 profile and predicts improved survival in breast carcinoma patients. Int Immunol. 2006;18:15911602 .

31. Dieu-Nosjean MC, Antoine M, Danel C, et al. Long-term survival for patients with non-small-cell lung cancer with intratumoral lymphoid structures. J Clin Oncol. 2008;26:4410-4417.

32. Kusuda T, Shigemasa K, Arihiro K, et al. Relative expression levels of Th1 and Th2 cytokine mRNA are independent prognostic factors in patients with ovarian cancer. Oncol Rep. 2005;13:1153-1158.

33. Tosolini M, Kirilovsky A, Mlecnik B, et al. Clinical impact of different classes of infiltrating $\mathrm{T}$ cytotoxic and helper cells (Th1, th2, treg, th17) in patients with colorectal cancer. Cancer Res. 2011;71:1263-1271.

34. Kondo T, Nakazawa H, Ito F, et al. Favorable prognosis of renal cell carcinoma with increased expression of chemokines associated with a Th1type immune response. Cancer Sci. 2006;97:780786.

35. Vesalainen S, Lipponen P, Talja M, Syrjanen K. Histological grade, perineural infiltration, tumourinfiltrating lymphocytes and apoptosis as determinants of long-term prognosis in prostatic adenocarcinoma. Eur J Cancer. 1994;30A:17971803.

36. Ubukata H, Motohashi G, Tabuchi $\mathrm{T}$, et al. Evaluations of interferon- $\gamma /$ interleukin- 4 ratio and neutrophil/lymphocyte ratio as prognostic indicators in gastric cancer patients. J Surg Oncol. 2010;102:742-747. 
37. Fridman WH, Pages F, Sautes-Fridman C, Galon J. The immune contexture in human tumours: impact on clinical outcome. Nat Rev Cancer. 2012;12:298-306.

38. Grivennikov SI, Greten FR, Karin M. Immunity, inflammation, and cancer. Cell. 2010;140:883-899.

39. Matsushita H, Vesely MD, Koboldt DC, et al. Cancer exome analysis reveals a T-cell-dependent mechanism of cancer immunoediting. Nature. 2012;482:400-404.

40. Teng MW, Galon J, Fridman WH, Smyth MJ. From mice to humans: developments in cancer immunoediting. J Clin Invest. 2015;125:33383346.

41. McGranahan N, Rosenthal R, Hiley CT, et al. Allele-specific HLA loss and immune escape in lung cancer evolution. Cell. 2017;171:1259-1271 e1211.

42. Tran E, Robbins PF, Lu YC, et al. T-cell transfer therapy targeting mutant KRAS in cancer. N Engl J Med. 2016;375:2255-2262.

43. Chowell D, Morris LGT, Grigg CM, et al. Patient HLA class I genotype influences cancer response to checkpoint blockade immunotherapy. Science. 2018;359:582-587.

44. Gabrilovich DI, Chen HL, Girgis KR, et al. Production of vascular endothelial growth factor by human tumors inhibits the functional maturation of dendritic cells. Nat Med. 1996;2:1096-1103.

45. Massague J. TGF $\beta$ in cancer. Cell. 2008;134: 215-230.

46. Dominguez-Soto A, Sierra-Filardi E, PuigKroger A, et al. Dendritic cell-specific ICAM-3grabbing nonintegrin expression on M2-polarized and tumor-associated macrophages is macrophageCSF dependent and enhanced by tumor-derived IL6 and IL-10. J Immunol. 2011;186: 2192-2200.

47. Bottcher JP, Bonavita E, Chakravarty $\mathrm{P}$, et al. NK cells stimulate recruitment of $\mathrm{cDCl}$ into the tumor microenvironment promoting cancer immune control. Cell. 2018;172:1022-1037.e14.

48. Topalian SL, Hodi FS, Brahmer JR, et al. Safety, activity, and immune correlates of anti-PD1 antibody in cancer. $\mathrm{N}$ Engl $\mathrm{J}$ Med. 2012;366:2443-2454.

49. Snyder A, Makarov V, Merghoub T, et al. Genetic basis for clinical response to CTLA-4 blockade in melanoma. $\mathrm{N}$ Engl $\mathrm{J}$ Med. 2014;371:2189-2199.

50. Boger C, Behrens HM, Kruger S, Rocken C. The novel negative checkpoint regulator VISTA is expressed in gastric carcinoma and associated with PD-L1/PD-1: a future perspective for a combined gastric cancer therapy? Oncoimmunology. 2017;6:e1293215.

51. Weitzenfeld P, Ben-Baruch A. The chemokine system, and its CCR5 and CXCR4 receptors, as potential targets for personalized therapy in cancer. Cancer Lett. 2014;352:36-53.

52. Kumar V, Patel S, Tcyganov E, Gabrilovich DI. The nature of myeloid-derived suppressor cells in the tumor microenvironment. Trends Immunol. 2016;37:208-220.

53. Tanaka A, Sakaguchi S. Regulatory T cells in cancer immunotherapy. Cell Res. 2017;27:109118.

54. Jose J, Naidu RM, Sunil PM, Varghese SS. Pathogenesis of Autoimmune Diseases: A Short Review. Oral Maxillofac Pathol J. 2014;5(1):434436. 
55. Fair-weather De L. Autoimmune disease mechanisms. Encyclopedia of life sciences. 2007:pp.1-6.

56. Robbins \& Cotran Pathologic Basis of Disease, $7^{\text {th }}$ Edition. Elsevier, Philadelphia USA: 171-189.

57. Carstensen B, Read SH, Friis S, et al. Cancer incidence in persons with type 1 diabetes: a fivecountry study of 9,000 cancers in type 1 diabetic individuals. Diabetologia. 2016;59(5):980-988.

58. Tsilidis KK, Allen NE, Appleby PN, et al. Diabetes mellitus and risk of prostate cancer in the European Prospective Investigation into Cancer and Nutrition. Int J Cancer. 2015;136:372-381.

59. Paschou SA, Papadopoulou-Marketou N, Chrousos GP, Kanaka-Gantenbein C. On type 1 diabetes mellitus pathogenesis. Endocr Connect. 2018;7(1):R38-R46.

60. Paschou SA, Petsiou A, Chatzigianni K, et al. Type 1 diabetes as an autoimmune disease: the evidence. Diabetologia. 2014;57(7):1500-1501.

61. Atkinson MA, Maclaren NK. The pathogenesis of insulin-dependent diabetes mellitus. $N$ Engl $J$ Med. 1994;331(21):1428-36.

62. Khalil I, d'Auriol L, Gobet M, et al. A combination of HLA-DQ beta Asp57-negative and HLA DQ alpha Arg52 confers susceptibility to insulin-dependent diabetes mellitus. J Clin Invest. 1990;85(4):1315-9.

63. Rowe RE, Leech NJ, Nepom GT, McCulloch DK. High genetic risk for IDDM in the Pacific Northwest. First report from the Washington State Diabetes Prediction Study. Diabetes. 1994; 43(1):87-94.

64. Baschal EE, Aly TA, Babu SR, et al. HLADPB $1 * 0402$ protects against type $1 \mathrm{~A}$ diabetes autoimmunity in the highest risk DR3DQB1*0201/DR4-DQB1*0302 DAISY population. Diabetes. 2007;56(9):2405-9.

65. Pugliese A, Gianani R, Moromisato R, et al. HLA-DQB1*0602 is associated with dominant protection from diabetes even among islet cell antibody-positive first-degree relatives of patients with IDDM. Diabetes. 1995;44(6):608-13.

66. Kübler K, Arndt PF, Wardelmann E, et al. HLA-class II haplotype associations with ovarian cancer. Int J Cancer. 2006;119:2980-2985.

67. Machulla HK, Müller LP, Schaaf A, et al. Association of chronic lymphocytic leukemia with specific alleles of the HLA-DR4:DR53:DQ8 haplotype in German patients. Int $J$ Cancer. 2001;92(2):203-207.

68. Anjos S, Polychronakos C. Mechanisms of genetic susceptibility to type I diabetes: beyond HLA. Mol Genet Metab. 2004;81(3):187-95.

69. Kavvoura FK, Ioannidis JP. CTLA-4 gene polymorphisms and susceptibility to type 1 diabetes mellitus: a HuGE Review and meta-analysis. Am J Epidemiol. 2005; 162(1):3-16.

70. Nakamoto N, Cho H, Shaked A, et al. Synergistic reversal of intrahepatic $\mathrm{HCV}$-specific CD8 $T$ cell exhaustion by combined PD-1/CTLA-4 blockade. PLoS Pathog. 2009;5(2):e1000313.

71. Curran MA, Montalvo W, Yagita H, Allison JP. PD-1 and CTLA-4 combination blockade expands infiltrating $\mathrm{T}$ cells and reduces regulatory $\mathrm{T}$ and myeloid cells within B16 melanoma tumors. Proc Natl Acad Sci U S A. 2010;107(9):4275-80.

72. Seidel JA, Otsuka A, Kabashima K. Anti-PD-1 and Anti-CTLA-4 Therapies in Cancer: Mechanisms of Action, Efficacy, and Limitations. Front Oncol. 2018;8:86. 
73. ASCO. Nivolumab or Ipilimumab Treatment May Increase Risk of Developing Autoimmune Joint and Tissue Disease. June 24, 2016. Retrieved from https://www.ascopost.com/News/41697 (cited on October 1, 2021)

74. Smyth D, Cooper JD, Collins JE, et al. Replication of an association between the lymphoid tyrosine phosphatase locus (LYP/PTPN22) with type 1 diabetes, and evidence for its role as a general autoimmunity locus. Diabetes. 2004;53(11):3020-3.

75. Zheng W, She JX. Genetic association between a lymphoid tyrosine phosphatase (PTPN22) and type 1 diabetes. Diabetes. 2005;54(3):906-8.

76. Brownlie RJ, Zamoyska R, Salmond RJ. Regulation of autoimmune and anti-tumour T-cell responses by PTPN22. Immunology. 2018;154(3):377-382.

77. Ho WJ, Croessmann S, Lin J, et al. Systemic inhibition of PTPN22 augments anticancer immunity. $J$ Clin Investig. 2021. DOI: 10.1172/JCI146950

78. Sabater L, Ferrer-Francesch X, Sospedra M, et al. Insulin alleles and autoimmune regulator (AIRE) gene expression both influence insulin expression in the thymus. J Autoimmun. 2005;25(4):312-8.

79. DeVoss JJ, Anderson MS. Lessons on immune tolerance from the monogenic disease APS1. Curr Opin Genet Dev. 2007;17(3):193-200.

80. Kalra R, Bhagyaraj E, Tiwari D, et al. AIRE promotes androgen-independent prostate cancer by directly regulating IL-6 and modulating tumor microenvironment. Oncogenesis. 2018:7(43). doi:10.1038/s41389-018-0053-7

81. Nguyen CTK, Sawangarun W, Mandasari M, et al. AIRE is induced in oral squamous cell carcinoma and promotes cancer gene expression. bioRxiv, 760959. https://doi.org/10.1101/760959

82. Bianchi F, Cecco De L, Triulzi T, et al. AIRE is expressed and associated with good prognosis in breast cancer. Cancer Res. 2016;(76):3924.

83. Wildin RS, Freitas A. IPEX and FOXP3: clinical and research perspectives. J Autoimmun. 2005;25:56-62.

84. Szylberg Ł, Karbownik D, Marszałek A. The Role of FOXP3 in Human Cancers. Anticancer Res. 2016;36(8):3789-94.

85. Yang S, Liu Y, Li M, et al. FOXP3 promotes tumor growth and metastasis by activating $\mathrm{Wnt} / \beta$ catenin signaling pathway and EMT in non-small cell lung cancer. Mol Cancer. 2017;16:124.

86. Zhang L, Xu J, Zhang X, et al. The Role of Tumoral FOXP3 on Cell Proliferation, Migration, and Invasion in Gastric Cancer. Cell Physiol Biochem. 2017;42:1739-1754.

87. Flanagan SE, Haapaniemi E, Russell MA, et al. Activating germline mutations in STAT3 cause early-onset multi-organ autoimmune disease. Nat Genet. 2014;46(8):812-814.

88. Avalle L, Camporeale A, Camperi A, Poli V. STAT3 in cancer: A double edged sword. Cytokine. 2017;98:42-50.

89. Laudisi F, Cherubini F, Monteleone G, Stolfi C. STAT3 Interactors as Potential Therapeutic Targets for Cancer Treatment. Int $J$ Mol Sci. 2018;19(6):1787. 
90. Huang K, Yanai A, Kang R, et al. Huntingtininteracting protein HIP14 is a palmitoyl transferase involved in palmitoylation and trafficking of multiple neuronal proteins. Neuron. 2004;44(6):977-86.

91. Berchtold LA, Størling ZM, Ortis F, et al. Huntingtin-interacting protein 14 is a type 1 diabetes candidate protein regulating insulin secretion and beta-cell apoptosis. Proc Natl Acad Sci U S A. 2011;108(37):E681-8.

92. Ducker CE, Griffel LK, Smith RA, et al. Discovery and characterization of inhibitors of human palmitoyl acyltransferases. Mol Cancer Ther. 2006;5(7):1647-1659.

93. Ko PJ, Dixon SJ. Protein palmitoylation and cancer. EMBO reports. 2018;19:e46666.

94. Kaur S, Mirza AH, Brorsson CA, et al, Hvidoere International Study Group. The genetic and regulatory architecture of ERBB3-type 1 diabetes susceptibility locus. Mol Cell Endocrinol. 2016;419:83-91.

95. Kiavue N, Cabel L, Melaabi S, et al. ERBB3 mutations in cancer: biological aspects, prevalence and therapeutics. Oncogene. 2019. doi:10.1038/s41388-019-1001-5

96. Mein CA, Esposito L, Dunn MG, et al. A search for type 1 diabetes susceptibility genes in families from the United Kingdom. Nat Genet. 1998;19(3):297-300.

97. Barratt BJ, Payne F, Lowe CE, et al. Remapping the insulin gene/IDDM2 locus in type 1 diabetes. Diabetes. 2004;53(7):1884-9.

98. Nejentsev S, Walker N, Riches D, et al. Rare variants of IFIH1, a gene implicated in antiviral responses, protect against type 1 diabetes. Science. 2009;324(5925):387-9.
99. Downes K, Pekalski M, Angus KL, et al. Reduced expression of IFIH1 is protective for type 1 diabetes. PLoS One. 2010;5(9):e12646.

100. Menser MA, Forrest JM, Bransby RD. Rubella infection and diabetes mellitus. Lancet. 1978;1:57.

101. Hober D, Sauter P. Pathogenesis of type 1 diabetes mellitus: interplay between enterovirus and host. Nat Rev Endocrinol. 2010;6:279-289.

102. Dotta F, Censini S, van Halteren AG, et al. Coxsackie B4 virus infection of beta cells and natural killer cell insulitis in recent-onset type 1 diabetic patients. PNAS. 2007;104(5115):46.

103. Schloot NC, Willemen SJ, Duinkerken G, et al. Molecular mimicry in type 1 diabetes mellitus revisited: T-cell clones to GAD65 peptides with sequence homology to Coxsackie or proinsulin peptides do not cross react with homologous counterpart. Human Immunology. 2001;62:299-309.

104. Bosch FX, Lorincz A, Munoz N, et al. The causal relation between human papillomavirus and cervical cancer. J Clin Pathol. 2002;55:244-265.

105. Brady G, MacArthur GJ, Farrell PJ. EpsteinBarr virus and Burkitt lymphoma. J Clin Pathol. 2007;60(12):1397-1402.

106. Virtanen SM, Saukkonen T, Savilahti E, et al. Diet, cow's milk protein antibodies and the risk of IDDM in Finnish children. Childhood Diabetes in Finland Study Group. Diabetologia. 1994;37:381.

107. Norris JM, Barriga K, Klingensmith G, et al. Timing of initial cereal exposure in infancy and risk of islet autoimmunity. JAMA. 2003;290:1713.

108. Parslow RC, McKinney PA, Law GR, et al. Incidence of childhood diabetes mellitus in Yorkshire, northern England, is associated with nitrate in drinking water: an ecological analysis. Diabetologia. 1997;40:550. 
109. Norris JM, Yin X, Lamb MM, et al. Omega-3 polyunsaturated fatty acid intake and islet autoimmunity in children at increased risk for type 1 diabetes. JAMA. 2007;298:1420.

110. Raab J, Giannopoulou EZ, Schneider S, et al. Prevalence of vitamin D deficiency in pre-type 1 diabetes and its association with disease progression. Diabetologia. 2014;57:902-908.

111. Altieri B, Muscogiuri G, Barrea L, et al. Does vitamin D play a role in autoimmune endocrine disorders? A proof of concept. Rev Endocr Metab Disord. 2017;18:335-346.

112. BfR Federal Institute for Risk Assessment. New pathogens in beef and cow's milk products: More research required. BfR Opinion. 2019;14: DOI 10.17590/20190606-133224

113. Beyan H, Wen L, Leslie RD. Guts, germs, and meals: the origin of type 1 diabetes. Curr Diab Rep. 2012;12:456-462.

114. Hu C, Wong FS, Wen L. Type 1 diabetes and gut microbiota: friend or foe? Pharmacol Res. 2015;98:9-15.

115. Sheflin AM, Whitney AK, Weir TL. Cancerpromoting effects of microbial dysbiosis. Curr Oncol Rep. 2014;16(10):406.

116. Buti L, Spooner E, Van der Veen AG, et al. Helicobacter pylori cytotoxin-associated gene A (CagA) subverts the apoptosis-stimulating protein of p53 (ASPP2) tumor suppressor pathway of the host. Proc Natl Acad Sci USA. 2011;108(22):923843.
117. Huycke MM, Moore D, Joyce W, et al. Extracellular superoxide production by Enterococcus faecalis requires demethylmenaquinone and is attenuated by functional terminal quinol oxidases. Mol Microbiol. 2001;42(3):729-40.

118. Gur C, Ibrahim Y, Isaacson B, et al. Binding of the Fap2 protein of Fusobacterium nucleatum to human inhibitory receptor TIGIT protects tumors from immune cell attack. Immunity. 2015;42(2):344-355.

119. Goodwin AC, Destefano Shields CE, Wu S, et al. Polyamine catabolism contributes to enterotoxigenic Bacteroides fragilis-induced colon tumorigenesis. Proc Natl Acad Sci USA. 2011;108(37):15354-15359.

120. Plottel CS, Blaser MJ. Microbiome and malignancy. Cell Host Microbe. 2011;10(4):32435 .

121. Doisneau-Sixou SF, Sergio CM, Carroll JS, et al. Estrogen and antiestrogen regulation of cell cycle progression in breast cancer cells. Endocr Relat Cancer. 2003;10(2):179-86.

122. Vivarelli S, Salemi R, Candido S, et al. Gut Microbiota and Cancer: From Pathogenesis to Therapy. Cancers (Basel). 2019;11(1):38.

123. Collins KK. The Diabetes-Cancer Link. Diabetes Spectrum 2014;27(4):276-280.

124. Handelsman Y, Leroith D, Bloomgarden ZT, et al. Diabetes and cancer: an AACE/ACE consensus statement. Endocr Pract 2013;19:675693.

125. Gallagher EJ, LeRoith D. The proliferating role of insulin and insulin like-growth factors in cancer. Trends Endocrinol Metab. 2010;21:610618. 
126. Vigneri P, Frasca F, Sciacca L, et al. Diabetes and cancer. Endocr Relat Cancer. 2009;16:11031123.

127. Becker S, Dossus L, Kaaks R. Obesity related hyperinsulinaemia and hyperglycaemia and cancer development. Arch Physiol Biochem. 2009;115:8696.

128. Kaaks R, Johnson T, Tikk K, et al. Insulin-like growth factor 1 and risk of breast cancer by age and hormone receptor status: a prospective study within the EPIC cohort. Int J Cancer. 2014;134:26832690.

129. Price AJ, Allen NE, Appleby PN, et al. Insulin-like growth factor-1 concentration and risk of prostate cancer: results from the European Prospective Investigation into Cancer and Nutrition. Cancer Epidemiol Biomarkers Prev. 2012;21:15311541.

130. Giovannucci E, Harlan DM, Archer MC, et al. Diabetes and cancer: a consensus report. $C A$ Cancer J Clin. 2010;60:207-221.

131. World Cancer Research Fund, American Institute for Cancer Research. Food, Nutrition, Physical Activity and the Prevention of Cancer: A Global Perspective. Washington, DC, American Institute for Cancer Research, 2007.

132. Wu Y, Antony S, Meitzler JL, Doroshow JH. Molecular mechanisms underlying chronic inflammation-associated cancers. Cancer Lett. 2014;345:164-173.

133. Pais R, Silaghi H, Silaghi AC, et al. Metabolic syndrome and risk of subsequent colorectal cancer. World J Gastroenterol. 2009;15:5141-5148. 